\title{
A Special Extrusion-shear Manufacturing Method for Magnesium Alloy Rods Based on Finite Element Numerical Simulation and Experimental Verification
}

\section{Ou Zhang}

Chongqing University of Technology

Hongjun Hu ( $\nabla$ hhj@cqut.edu.cn )

Chongqing University of Technology

Huiling Zhang

Chongqing University of Technology

Hui Zhao

Chongqing University of Technology

Ding-fei Zhang

Chongqing University of Technology

Zhongwen Ou

Chongqing University of Technology

\section{Research Article}

Keywords: wrought magnesium alloy, ES process, extrusion load, grain refinement

Posted Date: January 3rd, 2022

DOI: https://doi.org/10.21203/rs.3.rs-1206476/v1

License: (1) This work is licensed under a Creative Commons Attribution 4.0 International License.

Read Full License 


\section{Abstract}

To research the influences of process parameters on a special extrusion-shear

manufacture method for magnesium alloy rods, deform-3d software with finite element

simulations has been used to analyze the material flows of deformed magnesium alloys

AZ31B during the extrusion-shear (ES) process, as well as the grain sizes and

distribution of extrusion loads, stresses and strains, and blank temperatures. Temperature

fields, stress fields, strain fields and temperature fields varying with different blank

preheating temperatures, extrusion speed and extrusion ratios were simulated. Influences ofdifferent extrusion conditions and different die structures on microstructures of rods prepared by ES process has been researched. Extrusion forces decrease with the increasing extrusion temperatures, decreasing extrusion ratios, increasing die channel angles and decreasing friction coefficients. The flow velocities of metal in the ES die increase with development of ES process. Increasing the channel angles and reducing the friction factors would increase the outflow velocities of metal, but it has little effect on the uniformity of metal flow. The increase in friction and extrusion speed would increase the temperatures of the ES die. The ES process can prepare finer and more uniform microstructures than those prepared by direct extrusion under the same conditions.

\section{Introduction}

Magnesium alloys are regarded as green engineering materials in the 21 st century. In recent years, it has developed rapidly in many fields (such as the auto industry, aerospace industry and electronic industry). Moreover, its development prospects would become increasingly better[1]. Magnesium alloy enjoys a great reputation as the lightest metal in all the structural metallic materials, because its density is only $1.74 \mathrm{~g} / \mathrm{cm}^{3}$, which is $2 / 3$ of that for aluminum. Magnesium alloys are $78.9 \%$ lighter than steel[2-4]. The features of magnesium and magnesium alloys include lower density, good damping properties along with damping effects, higher specific modulus along with a good quality of thermal conduction and electromagnetic shielding, and excellent machining quality. Rolling, forging and extrusion are the three main deformation methods of magnesium alloys. Cracks easily form in magnesium alloys during rolling. Thus, the reductions of each rolling pass are restricted, which results in a small deformation quantity and a nonideal warping effect. A magnesium alloy is subjected to triaxial compression stress during extrusion. The strong compressive stress that comes from three triaxial compression stresses provides a large amount of deformation, which is under hydrostatic pressure for the extrusion process of magnesium alloy and strongly improves its deformation capacity[5-8]. Compared with rolling and forging, the size of the extrusion product can be controlled in a quite accurate range. At the same time, its surface quality of products is good. Therefore, extrusion has been a significant way to produce 
magnesium alloy products. Although the traditional extrusion process tends to be mature, the effects of grain refinements for magnesium alloys are not obvious.

To obtain a better grain refinement effect, a large extrusion ratio of extrusion has sometimes been used. Extrusion with a larger extrusion ratio can produce a larger stress-strain during the procedure of direct extrusion, which would reduce the service lives of the die. Extrusion can cause a second or multiple deformations to improve the effects of grain refinements. However, in this way, the designs and manufacturing of dies would be increased, and the production efficiency would be poor. At the same time, industrial production costs are rising.

Moreover, some parameters of the experiments such as flow stresses and strain rates are hard to measure by testing. Therefore, finite element modeling plays a vital role in verifying whether the new forming modes and technology parameters are reasonable[9-12].

To illustrate the potential industrial application of the ES process, ES dies have been designed, and ES processes with different process parameters have been simulated. The aim of the present study is to reveal the microstructure evolution and clarify the grain refinement mechanism in AZ31 magnesium alloy during the ES process. DEFORM ${ }^{\mathrm{TM}}-3 \mathrm{D}$ finite element software was employed to simulate distributions of extrusion loads, stresses and strains, and blank temperatures varying with different blank preheating temperatures, extrusion speeds and extrusion ratios during the ES process. Microstructures of AZ31 magnesium alloy sampled from the extruded tubes were observed. Deformed microstructures of evolution for AZ31 magnesium alloy with different manufacturing condtions were studied to analyze the deformation mechanisms of the ES process.

\section{Simulation And Experimental Conditions Of Es Process 2.1 Material Property}

Materials for simulations and experiments are commercial AZ31B magnesium alloy (Mg-3\%Al-1\%Zn, wt), and the specific components are shown in Table.1. The billets were annealed at $400^{\circ} \mathrm{C}$ for 15 hours before extrusion started and cooled to room temperature in the furnace to obtain homogeneous microstructures of AZ31 magnesium alloy. The die structures include extrusion die, container, and extrusion rod, and they are made of $\mathrm{H} 13$ hot-work die steel.

Table 1

Mass fraction of main elements in AZ31 magnesium alloy $\%$ [13]

\begin{tabular}{|lllll|}
\hline element & $\mathbf{A l}$ & $\mathbf{Z n}$ & $\mathbf{M n}$ & $\mathbf{M g}$ \\
\hline Mass fraction\% & $2.5 \llbracket 3$ & $0.7 \otimes 1.3$ & $>0.20$ & bal \\
\hline
\end{tabular}

\subsection{Die structures}


The design idea of the ES die is based on the combination of extrusion and shear, and the ES process would increase the compressive stresses and shear stresses of magnesium alloy billets. Consequently, the ductility of magnesium alloy improved. According to the principle of more pressure and better plasticity, the back pressure is increased in the procedure of metal forming, and thus ductility is enhanced. ES process involves a huge number of parameters. The parameters of die structures, such as extrusion ratios. For the experimental condition parameters, there are extrusion temperatures, extrusion speed, lubrication and so on. As a consequence, the finite element simulations and experimental parameters are shown in Table 2. Through the simulation of extruding forces, metal flows and temperature distributions under different parameter conditions, the influences of extrusion parameters on the ES process were investigated.

Table 2

Parameters used for the numerical simulation

\begin{tabular}{|ll|}
\hline Length of billet $(\mathrm{mm})$ & 50 \\
\hline Billet diameter $(\mathrm{mm})(\mathrm{cast}$, uniform state) & 80 \\
\hline Extrusion container diameter $(\mathrm{mm})$ & 85 \\
\hline Length of work-land $(\mathrm{mm})$ & 5 \\
\hline Extrusion ratio & $12,18,22$ \\
\hline Billet preheated temperature $\left({ }^{\circ} \mathrm{C}\right)$ & $370,400,420$ \\
\hline The die preheated temperature $\left({ }^{\circ} \mathrm{C}\right)$ & $350,380,400$ \\
\hline Extrusion speed $(\mathrm{mm} / \mathrm{s})$ & $5,10,20$ \\
\hline Friction coefficient between blank and die $($ constant shear stress friction) & $0.08,0.3,0.7$ \\
\hline Thermal conductivity between die and blank $\left(\mathrm{N} /{ }^{\circ} \mathrm{Cs}\right.$ mm $\left.{ }^{2}\right)$ & 11 \\
\hline Total number of extrusion rod units & 2000 \\
\hline Total number of blank units & 8000 \\
\hline Total number of die units & 20000 \\
\hline Minimum unit size/mm & 1 \\
\hline Grid density type & Relative \\
\hline Relative penetration depth & 0.7 \\
\hline
\end{tabular}

Geometric models for finite element simulations are composed of workpieces, top-die, bottom die. Deform-3D is not equipped with the functions of 3D modeling, workpiece, 
top die and bottom die were built with the 3D modeling software UG in this research. The geometric models of the workpiece and dies are shown in Fig. 1. The workpieces and models are symmetrical, and we choose half of the models to conduct simulations.

Fig.1 Geometric and FEM model for ES process

\section{Numerical Simulation Results And Analysis}

\subsection{Varieties of extrusion forces with extrusion strokes}

During the ES process, the extrusion force is the key element to determine whether the blank can be successfully extruded. The extrusion force is affected by process parameters such as the extrusion temperature, extrusion speed and friction conditions. It can also be influenced by the composition and states of the materials, as well as the die structures. To successfully obtain good-quality of magnesium alloys and extrusion, the parameters of the extrusion process die structures should be optimized. Thus, the change in extrusion loads was analyzed by using FEM software to simulate the ES process in different situations. During the ES process of AZ31 magnesium alloy with a preheated billet temperature of $370^{\circ} \mathrm{C}$, the changing situations of extruding forces and equivalent stresses are shown in Fig. 3. From tendencies of extruding forces changing with time, variations of extruding forces, The extrusion forces vary regularly with the changing of extrusion steps.In this process, the main process of magnesium alloy includes upsetting,sizing, primary shearing, secondary shearing and shaping.During the whole process, equivalent stresses increase.It can be seen from Fig. $2 b$ shows that the extrusion forces increase rapidly, and the equivalent stress is as high as $112 \mathrm{MPa}$ in the partial zone.

Fig. 2 Varieties of extrusion forces with extrusion strokes and equivalent stresses of the AZ31 alloy during the ES process with an extrusion ratio of 12 and a preheating temperature of $370^{\circ} \mathrm{C}$, (a) upsetting,(b) sizing,(c) primary shearing, (d) secondary shearing and shaping.

\subsection{The variation in loads during the ES process with different preheating temperatures}

To study the variation rules of extrusion forces with different extrusion ratios, curves of extrusion load and extrusion time are shown in Fig. 3. Throughout the whole ESprocess, the variation laws of the extruding force curves are nearly consistent.Increasing temperatures hardly influence the extruding force during the initial stage of upsetting. We can see from the figure that the upsetting force is basically coincident at different temperatures.

It can be observed in the curves that upsetting forces are basically the same under different temperatures. The extrusion forces of direct extrusion at different temperatures also coincide with each other, but as the extrusion forces increase with the development of the ES process. Fig. 3 shows that the extrusion forces increase with decreasing preheated billet temperatures. During the primary shearing and secondary 

same.

\subsection{The load varieties of the ES process with different extrusion ratios}

To study the changing rule of extruding forces varying with different extrusion ratios, the ES process with a preheated billet temperature of $400^{\circ} \mathrm{C}$ was simulated, and extrusion

ratios are 12, 22 and 32, respectively. The extrusion forces of the ES process with different extrusion ratios are presented in Fig. 4. Maximum extrusion forces increase with the rising of extrusion ratios. The extrusion force of the ES process with an extrusion ratio of 22 is as large as 100 tons. The extrusion force of the ES process with extrusion ratio 32 is approximately 80 tons larger than that of the ES process with extrusion ratio 22 . The curves of extrusion forces with different

extrusion ratios coincide in the initial extrusion stages of all ES processes. This shows that extrusion forces in the upsetting stage are independent of the extrusion ratios. During the direct extrusion stage, different extrusion ratios correspond to different extrusion force curves, and the curves of the extrusion forces are almost parallel. When the extrusion ratio is 12 and 22, platform curves of extrusion forces can be observed. When the extrusion ratio increases to 32 , the plateau of extrusion forces becomes an inflection point. This shows that the extrusion ratio is smaller, and the changing rules of different stages during the ES process are more significant. During the stable extrusion stage, fluctuations in extrusion forces are smaller if the extrusion ratios are smaller.

\subsection{Effects of different channel angles on extrusion forces}

The ES die contains an ordinary direct extrusion zone and an equal channel angular zone. As a main parameter of equal channel extrusion, the channel angles of the die have certain effects on the extrusion forces. The changing curves of extruding forces with different channel angles and extrusion ratios of 12 and billet preheating temperature of $420^{\circ} \mathrm{C}$ are shown in Fig. 5.

Because the channel angle is located in the equal-channel extrusion zone, the extrusion force is not affected by the upsetting stage, which is before the equal-channel extrusion zone and the ordinary extrusion zone. Extrusion platforms of the extrusion force curves corresponding to different channel angles coincide. In the equal channel extrusion zone, the slopes of rising for extrusion forces are different due to the influences of the angles. When the channel angle is smaller, the slope of the extrusion force increase is larger, and the final stable extrusion force is larger[14-20].

\subsection{Flow velocities of billets in different zones of ES die}

While blanks are extruded, blanks would be deformed with the pushing of punches and the constraints of dies. Metal flows through the ES die with different speeds and ways. During the ES process, the deformation behavior of the blank is related to the metal flow velocities and methods. To preferably study 
the new-type ES process, simulations and analyses of velocity fields have been conducted. The diameter of the blank is smaller than that of the cylinder, the ingot is upset first in the extrusion cylinder during the initial extrusion of the ES process, and the metal flows to fill the whole extrusion cylinder with pushing of the extrusion punches and the constraint of the die. Because the billet only underwent upsetting deformation and the amount of deformation was small, the velocities of metal flows changed little during the upsetting stage, and the velocities were roughly the same as those of extrusion punches.

When the blank undergoes deformation in the ordinary direct extrusion zone, the blank is compressed, and the diameter decreases in the radial direction. At the same time, the cross-sectional area of the blank decreases in ordinary direct extrusion. When metal is deformed, elastic deformation is often neglected, and more attention is given to plastic strains because the small elastic deformation occurs.

On the basis of volume constancy in plastic strains, when cross-sectional areas of blank decrease, the amount of metal in cross-sectional area increases per unit time. It means the flow velocities of metal increase.It can be known from the Fig. 7 shows that the flow velocities of metal in the middle of the blank increases gradually from the upsetting zone to the ordinary direct extrusion zone. It increases from the initial $10 \mathrm{~mm} / \mathrm{s}$ to a maximum of $55 \mathrm{~mm} / \mathrm{s}$.

In the equal channel angular zone, the reasons for decreasing flow velocities are frictional actions and inhibition of channel angularity on metal flows. From Fig. 8, the flow velocities of the metal decrease obviously compared with those before the primary shearing zone. There are obvious velocity gradients in the metal flow in the corner zones.

The flow velocities of metals which are in the second angular zone are shown in Fig. 9. The flow velocities of metal would change as it passed through the two shearing zones. Obvious gradients of velocities exist in the second shearing zone, which are the same as those in the first angular zone. Different from the gradients of velocities in the first angular zone, the gradients of velocities in the second angular zone are incremental. The second angle has an inhibition on metal flows, which means that the second angular zone may exert back pressure on the metal in the first angular zone, so the flow velocity would decrease. However, the blank will not be borne back pressure after the blank passes the second angular zone, and the flow velocities of the metal increases.

In the stable extrusion stage, the distribution of metal flow velocities is shown in the Fig. 10. During the stable extrusion stage, the extruding force remains within a small range of fluctuations. From the figure, we know that in a stable extrusion, the metal velocities are consistent.

(a) (b) (c)

(d) (e)

Figure 6 Distributions of metal flow velocities during different stages (a)upsetting stage, (b) ordinary direct extrusion zone, (c) primary shearing zone, (d) secondary corner region, (e)stable extrusion stage. 


\subsection{Influences of different frictional conditions on metal flows}

The influences of the ES die with an extrusion ratio of 12 and channel angle of $120^{\circ}$ on the metal flows under different friction conditions are shown in Fig. 7. With the increasing friction factors, the flow velocities of the metal decrease. Flow velocities are almost coincident in the whole TD direction. There is no remarkable increase in flow velocities in this direction when the friction factors increase.

\subsection{Variation in the temperature field during the ES process}

Temperature would change due to the friction actions between the blank and die during the ES process, and heat transfer effects in air space are also a reason. $90 \%$ deformation energy billet during the plastic deformation process might be lost with heating. To research the variation in the temperature gradient during the ES process, deform software to simulate the ES process was used. The thermal conductivity between the die and blank was set to $11 \mathrm{~N} /{ }^{\circ} \mathrm{Cs} . \mathrm{mm}^{2}$. Different friction factors $(0.08,0.3,0.7)$, different extrusion ratios $(12,18,22)$, different extrusion velocities $(2 \mathrm{~mm} / \mathrm{s}, 10 \mathrm{~mm} / \mathrm{s}, 20 \mathrm{~mm} / \mathrm{s})$ and different initial temperatures $\left(350^{\circ} \mathrm{C}, 380^{\circ} \mathrm{C}, 400^{\circ} \mathrm{C}\right)$ are adopted to analyze the influences of temperature fields during ES process with different technological conditions[21-22].

During the ES process, one of the sources of heat that increases the temperature is the friction action between the die and blank. ES process was simulated with extrusion ratio 12. And those simulations are conducted with the three different friction coefficients, which are low friction $(m=0.08)$, lubrication $(m=0.3)$ and without lubrication $(\mathrm{m}=0.7)$.

Temperature variations with different friction coefficients are shown in Figure 8. From the figure, when the friction coefficient is smaller, the friction is small, and the temperature rise is smaller. Thus, friction would not only influence extruding forces, but also affect the temperature distribution of the extrusion die. The temperature of the die increases with increasing friction coefficients[23-25].

\subsection{Temperature variation with different extrusion speeds}

The temperature variations are shown in Fig. 9, and the different extrusion speeds are $5 \mathrm{~mm} / \mathrm{s}, 10 \mathrm{~mm} / \mathrm{s}$ and $20 \mathrm{~mm} / \mathrm{s}$. From the curves, it can be concluded that the temperatures of the blanks would increase with increasing extrusion speeds. Heat produced

between the blank and mold can not transmit with increasing extrusion speed. Vigorous deformation would produce more heat, and prompt die temperatures and blank rise[26-27].

Figure 9 Temperature variations of the die with different extrusion speeds

\section{Microstructures Observation}




\subsection{Effects of extrusion methods on microstructures}

Figure 10 shows the distribution of microstructures in the longitudinal section of the samples fabricated by ordinary direct extrusion and the ES process with a billet preheating temperature of $370^{\circ} \mathrm{C}$. It can be seen from the microstructures that there are definite differences in the microstructures.

After the samples are prepared by ordinary direct extrusion, the microstructures of the sample edges are very fine and uniform due to the occurence of dynamic recrystallization. Owing to the small deformation in the central zone of extruded rods, only some zones reach the critical strains of dynamic recrystallization. Full dynamic recrystallization would produce fine grains, and dynamic recrystallization did not occur due to slight deformation in other regions. The microstructures of the central rods consist of mixed-grain microstructures that are fined dynamic recrystallization grains surrounded by coarse primary grains, as shown in Fig. 10a.

- (b)

Figure 10 Microstructures of rods prepared by different processes with billets preheated at $370^{\circ} \mathrm{C},(\mathrm{a})$ direct extrusion and (b) ES process.

\subsection{Effects of billet preheating temperatures on microstructures}

Figure 11 shows that the average grain size obtained by the ES process with the billet preheating temperature. From billet preheating temperatures of $370^{\circ} \mathrm{C}$ to $420^{\circ} \mathrm{C}$, the average grain size obtained by ordinary direct extrusion increases continuously with increasing extrusion temperature, and the increasing trend is basically linear. For ES-extruded rods, the average grain size changes little when the temperature increases from $370^{\circ} \mathrm{C}$ to $400^{\circ} \mathrm{C}$, but increases significantly when the temperature increases from $400^{\circ} \mathrm{C}$ to $420^{\circ} \mathrm{C}$. At the same time, Figure 11 shows that the average grain sizes of ES-extruded rods with three different billet preheating temperatures are much refiner than those of ordinary direct extruded rods. It is obvious that the ES process can prepare for finer and more uniform microstructures than those prepared by direct extrusion under the same conditions.

\section{Conclusion}

Deform-3D FEM software was adopted to simulate direct extrusion and ES processes with different extrusion ratios, billet preheating temperatures, extrusion speeds, and friction coefficients between the blank and die. The simulations involve extruding forces, strain fields, velocity fields and temperature fields during the ES process. Extrusion experiments and microstructure observations were performed under the same simulation conditions.

(1)The extrusion pressure changes with the structures of the ES die. There are two platforms in curves of load-time. Extrusion forces decrease with increasing extrusion temperatures, decreasing extrusion ratios, 
increasing die channel angles and decreasing friction coefficients.

(2) The metal flow velocity distribution in different zones of the ES die was observed through simulation, and metal flows were restricted by the die structures of the ES process. The flow velocities of metal in the ES die increase with the development of the ES process. However, the flow velocities of the metal at the first turning corner decreased because the second corner exerts back pressure on the metal. Increasing the channel angles and reducing the friction factors would increase the outflow velocities of metal,but it has little effect on the uniformity of metal flow.

(3)The temperature field changes with different friction conditions and different extrusion speeds were analyzed. The increase in friction and extrusion speed would increase the temperatures of the ES die. If the preheated billet temperature is higher, the temperatures of the ES die would be higher, but the amplitude of the temperature rise would decrease.

(4) The ES process can prepare finer and more uniform microstructures than those prepared by direct extrusion under the same conditions.

\section{Declarations}

Acknowledgment

This work was supported by The Chongqing talent plan (CQYC202003047), and the Chongqing Natural Science Foundation Project of cstc2018jcyjAX0249 and cstc2018jcyjAX0653 ).

\section{DECLARATIONS}

-Ethical Approval

No animals have been used in any experiments.

-Consent to Participate

There were no humans who were used in any experiments.

Consent to Publish

The Author confirms:

- that the work described has not been published before (except in the form of an abstract or as part of a published lecture, review, or thesis);

- that it is not under consideration for publication elsewhere;

- that its publication has been approved by all coauthors, if any;

- that its publication has been approved (tacitly or explicitly) by the responsible authorities at the institution where the work is carried out. 
The author agrees to publication in the journal indicated below and also for publication of the article in English by Springer in Springer's corresponding English-language journal.

The copyright of the English-language article is transferred to Springer effective if and when the article is accepted for publication. The author warrants that his/her contribution is original and that he/she has full power to make this grant. The author signs for and accepts responsibility for releasing this material on behalf of any and all coauthors. The copyright transfer covers the exclusive right to reproduce and distribute the article, including reprints, translations, photographic reproductions, microform, electronic form (offline, online) or any other reproductions of similar nature.

After submission of the agreement signed by the corresponding author, changes of authorship or in the order of the authors listed will not be accepted by Springer.

Journal:

Title in English :The International Journal of Advanced Manufacturing Technology

Title of article: A special extrusion-shear manufacturing method for magnesium alloy rods based on finite element numerical simulation and experimental verification

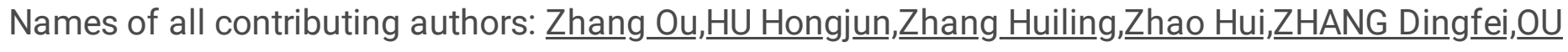
Zhongwen

Corresponding author's signature:

Simage

Date: $\quad 2021-12-5$

-Authors Contributions

- Hongjun $\mathrm{Hu}$ is the corresponding author of this paper who wrote the paper.

- Ou Zhang done the experiments in this paper.

- Huiling Zhang done the simulation in this paper.

- Hui Zhao done the testings in this paper.

- Dingfei Zhang researahed the microstructure analysises in this paper

- Zhongwen Ou researahed the microstructure analysises in this paper

-Funding

This work was supported by the Chongqing talent plan (CQYC202003047), and the Chongqing Natural Science Foundation Project of cstc2018jcyjAX0249 and cstc2018jcyjAX0653 ). 
I confirm that I have mentioned all organizations that funded my research in the Acknowledgments section of my submission, including grant numbers where appropriate.

-Competing Interests

The authors declare no competing nonfinancial/financial interests.

-Availability of data and materials

The raw/processed data required to reproduce these findings cannot be shared at this time as the data also form part of an ongoing study.

Acknowledgment

This work was supported by the Chongqing talent plan (CQYC202003047), and the Chongqing Natural Science Foundation Project of cstc2018jcyjAX0249 and cstc2018jcyjAX0653).

\section{References}

[1]DU Yu-zhou, LIU Dong-jie, GE Yan-feng,JIANG Bai-ling(2020) Effects of deformation parameters on microstructure and texture of Mg-Zn-Ce alloy.Transactions of Nonferrous Metals Society of China 30: 2658-2668 https://doi.org/10.1016/S1003-6326(20)65410-3

[2]Liu D, Liu ZY,Wang ED(2015) Evolution of twins and texture and its effects on mechanical properties of AZ31 magnesium alloy sheets under different rolling process parameters[J]. Trans Nonferrous Metals Soc China 25(11):3585-3594

https://doi.org/10.1016/S1003-6326(15)63999-1

[3] Ding Y.L,Wang J.G,Zhao M,Ju D.Y.(2018)Effect of annealing temperature on joints of diffusion bonded $\mathrm{Mg} /$ Al alloy.Transactions of Nonferrous Metals Society of China 28(2):251258.https://doi.org/10.1016/S1003-6326(18)64658-8

[4] Tian,Y.,Hu,H.,Zhang,D.(2021)A novel severe plastic deformation method for manufacturing Al/Mg bimetallic tube. Int J Adv Manuf Technol 116:2569-2575

https://doi.org/10.1007/s00170-021-07513-5

[5] Huang H, Liu H,Wang C, Sun J, Bai J, Xue F, Jiang J, Ma A (2019) Potential of multipass ECAP on improving the mechanical properties of a high-calcium-content Mg-Al-Ca-Mn alloyJournal of Magnesium and Alloys(7):617-627

https://doi.org/10.1016/j.jma.2019.04.008

[6]GUO LL, FU F (2018) Effect of deformation mode, dynamic recrystallization 
and twinning on rolling texture evolution of AZ31 magnesium alloy. Trans Nonferrous Metals Soc China 28:1094-1102 https://doi.org/10.1016/S1003-6326(18)64745-4

[6] Chen, Q., Zhang, X., Lin, J.,Zhan H.,Zhao Z.,Xie Z.,Yuan B.(2019)Isothermal closed-die forming process of magnesium alloy upper receiver: numerical simulation and experiments. Int $\mathrm{J}$ Adv Manuf Technol 102:685-694 https://doi.org/10.1007/s00170-018-03209-5

[8]Iwaszko,J.,Kudła,K.(2021)Microstructure, hardness, and wear resistance of AZ91 magnesium alloy produced by friction stir processing with air-cooling.Int J Adv Manuf Technol 116: 1309-1323 https://doi.org/10.1007/s00170-021-07474-9

[9]Öğüt, S., Kaya, H., Kentli, A. ,Uar M(2021)Applying hybrid equal channel angular pressing (HECAP) to pure copper using optimized Exp.-ECAP die.Int J Adv Manuf Technol 116:3859-3876 https://doi.org/10.1007/s00170-021-07717-9

[10]LI Xin , JIANG Jing-hua , ZHAO Yong-hao , MA Ai-bin , Dao-jing WEN, Yun-tian ZHU(2015)Effect of equal-channel angular pressing and aging on corrosion behavior of ZK60 Mg alloy.Transactions of Nonferrous Metals Society of China25(12):3909-3920 https://doi.org/10.1016/S1003-6326(15)64038-9

[11]AHMADI Siroos,ALIMIRZALOO Vali,FARAJI Ghader,DONIAVI Ali(2021)Properties inhomogeneity of AM60 magnesium alloy processed by cyclic extrusion compression angular pressing followed by extrusion.Transactions of Nonferrous Metals Society of China21(3):65527-65529

https://doi.org/10.1016/S1003-6326(21)65527-9

[12]Önder AYER(2019)A.forming load analysis for extrusion process of AZ31 magnesium. Transactions of Nonferrous Metals Society of China 29(4):741-753 https://doi.org/10.1016/S1003-6326(19)64984-8

[13]Yang Yan , Xiong Xiaoming,Chen Jing,Peng Xiaodong ,Chen Daolun , Pan Fusheng (2021)Research advances in magnesium and magnesium alloys worldwide in 2020. Journal of Magnesium and Alloys 9(3):705-747 https://doi.org/10.1016/j.jma.2021.04.001

[14]KUMAR S. DHARANI \& KUMAR S. SURESH.(2021)Effect of heat treatment conditions on ballistic behaviour of various zones of friction stir welded magnesium alloy joints[J]. Transactions of Nonferrous Metals Society of China(1)

https://doi.org/10.1016/S1003-6326(20)65484-X

[15]Ji, YF., Duan, JR., Li, HY.,Liu YM『Peng W,Ma LF(2021)Improvement of edge crack damage of magnesium alloy by optimizing the edge curve during cross variable thickness rolling. Int $\mathrm{J}$ Adv Manuf Technol 112:1993-2002 https://doi.org/10.1007/s00170-020-06517-x

[16]AHMADI Siroos,ALIMIRZALOO Vali,FARAJI Ghader \& DONIAVI Ali(2021)Properties inhomogeneity of AM60 magnesium alloy processed by cyclic extrusion compression angular pressing followed by 
extrusion.Transactions of Nonferrous Metals Society of

China21(3):65527-65529.https://doi.org/10.1016/S1003-6326(21)65527-9

[17]DU Pei-hua,SHUSAKU F, TSUYOSHI F.(2020)Microstructure and performance of biodegradable magnesium alloy Tubes fabricated by Local-heating-assisted dieless drawing.Journal of Magneisum and Alloys 8(3):614-623

https://doi.org/10.1016/j.jma.2020.05.009

[18] Huang J. F.,Song G.L,Zhu Y. X,Zheng D. J,Wang Z.M.(2021)The anodically polarized Mg surface products and accelerated hydrogen evolution,Journal of Magnesium and Alloys

https://doi.org/10.1016/j.jma.2021.05.008

[19] Yuan X, Zhang J,LianY,,DuCヌXu W(2018)Research progress of residual stress determination in magnesium alloys, Journal of Magnesium and Alloys(6):238-244

https://doi.org/10.1016/j.jma.2018.06.002

[20] YANG Xia-wei ,FENG Wu-yuan ,LI Wen-ya,YAO Shuo-tian (2019)Microstructure and properties of probeless friction stir spot welding of AZ31 magnesium alloy joints.Transactions of Nonferrous Metals Society of China(11), doi:10.1016/S1003-6326(19)65136-8.

[21] Li, X.B., Li, F. \& Li, X.W.(2018)Effect of different temperatures on deformation characteristics of AZ31 magnesium alloy by continuous variable cross-section direct extrusion. Int $\mathrm{J}$ Adv Manuf Technol 95:4623-4628 https://doi.org/10.1007/s00170-017-1557-6

[22]Wu, S., Sun, T., Shen, Y.,Yan Y, Ni R, Liu W(2021)Conventional and swing friction stir spot welding of aluminum alloy to magnesium alloy. Int J Adv Manuf Technol 116: 2401-2412 https://doi.org/10.1007/s00170-020-06548-4

[23]GUO F,ZHANG D.F,YANG X.S(2015)Microstructure and texture evolution of AZ31 magnesium alloy during large strain hot rolling.Transactions of Nonferrous Metals Society of China25 (01): 14-21 https://doi.org/10.1016/S1003-6326(15)63573-7

[24]Campanella, D., Buffa, G., Lo Valvo, E. et al.(2021) A numerical approach for the modelling of forming limits in hot incremental forming of AZ31 magnesium alloy. Int J Adv Manuf Technol 114:3229-3239 . https://doi.org/10.1007/s00170-021-07059-6

[25]Tian Y, Hu HJ, Zhang DF (2021) A novel severe plastic deforma-

tion method for manufacturing Al/Mg bimetallic tube, Int J Adv Manuf Technol 2021 https://doi.org/10.1007/s00170-021-07513-5. 
[26]Moradnezhad, S., Razaghian, A., Taghiabadi, R. et al.(2019)Effect of Ca additions on evolved microstructures and subsequent mechanical properties of a cast and hot-extruded $\mathrm{Mg}-\mathrm{Zn}-\mathrm{Zr}$ magnesium alloy. Int J Adv Manuf Technol 104:4265-4275. https://doi.org/10.1007/s00170-019-04260-6

[27]Wang, Y.P., Li, F., Li, X.W.(2020)Effect of extrusion ratio $(\lambda)$ on dynamic recrystallization of AZ31 magnesium alloy bending products prepared by staggered extrusion (SE). Int J Adv Manuf Technol 108:289-297. https://doi.org/10.1007/s00170-020-05416-5

[28]Han, S., Li, Z., Wang, Z.,Li Y (2021) Review on joining processes of magnesium alloy sheets. Int J Adv Manuf Technol. https://doi.org/10.1007/s00170-021-07981-9

[29]Wang, Y., Li, F., Li, X.W,Fang,W.B.(2019)Process model and experimental analysis of circumferential extending extrusion forming for magnesium alloy sheet. Int J Adv Manuf Technol 102:1547-1556 . https://doi.org/10.1007/s00170-018-03232-6

[30]Xia X.S,Chen Q,Li H ,Tan Y.J (2018) Hot forging process design, microstructure, and mechanical properties of cast Mg-Zn-Y-Zr magnesium alloy tank cover. Int J Adv Manuf Technol 94:4199-4208. https://doi.org/10.1007/s00170-017-1146-8

\section{Figures}

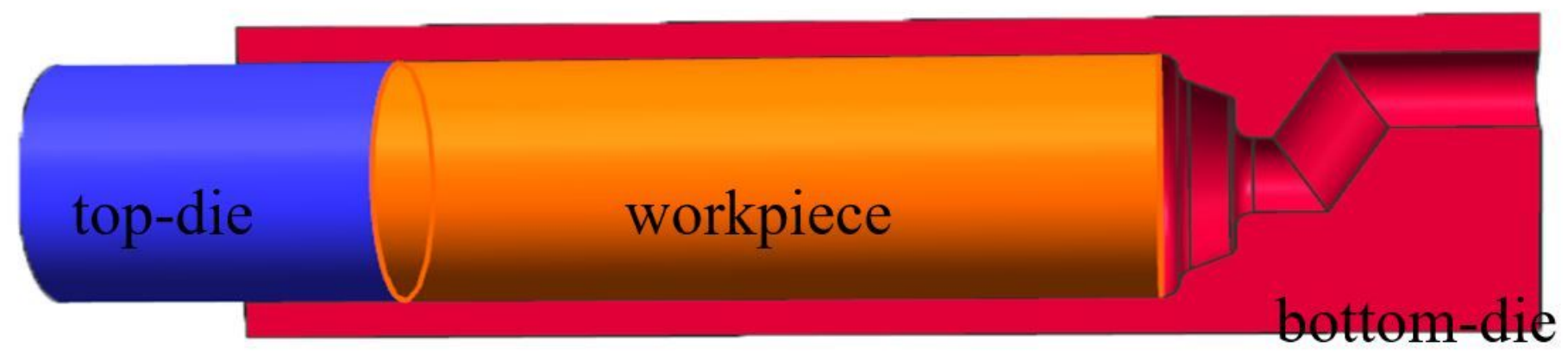

\section{Figure 1}

Geometric and FEM model for ES process 
(a)

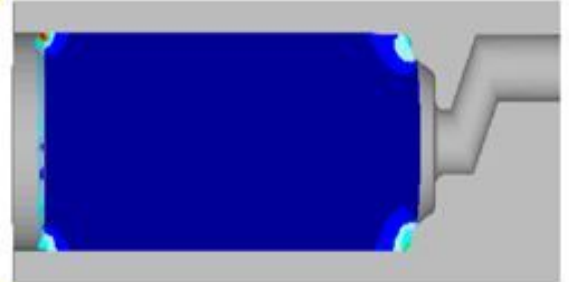

Load Prediction

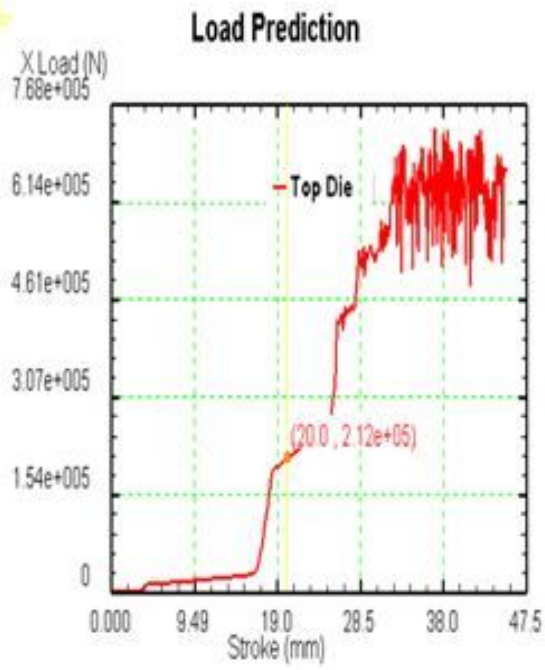

(c)

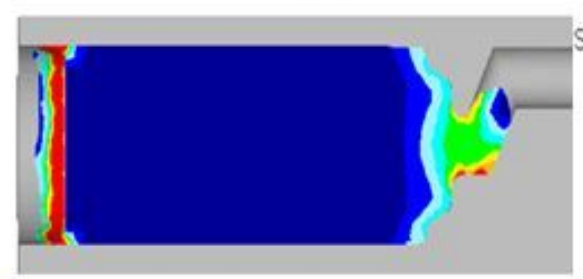

Load Prediction

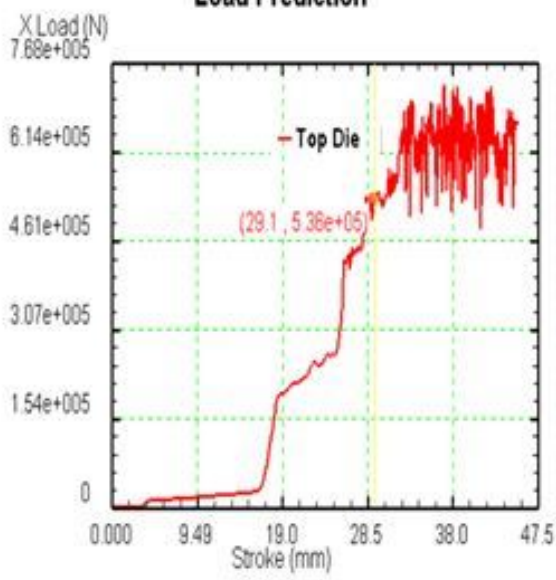

Srañ E Ëetchre (rmmlmm) (b)

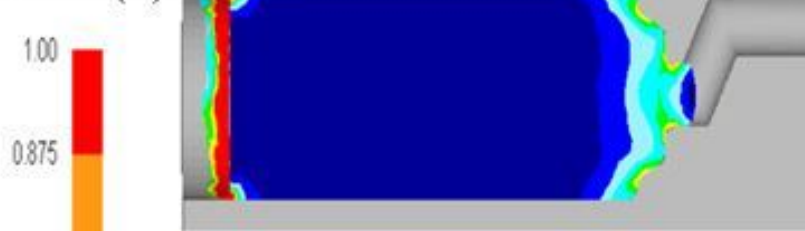

Load Prediction \begin{tabular}{c} 
XLodid(N) \\
$7680+005$ \\
\hline
\end{tabular}

0.625

0.500

0375

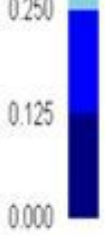

0,000

train - Effective (mmmmm) (d)
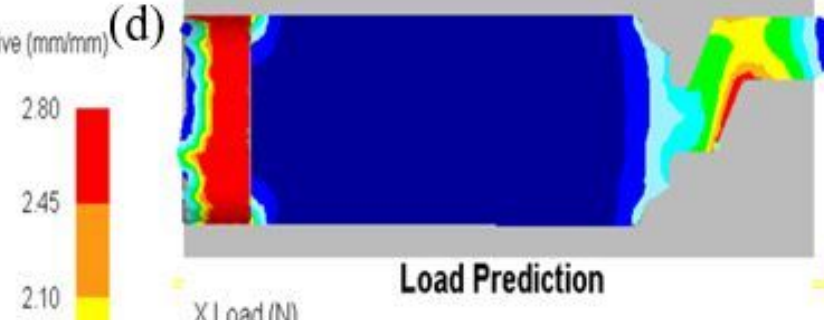

Load Prediction

$X$ Load (N)

$768 \mathrm{e}+000$

1.75
1.40
1.05
0.700
0.350
0.000
Strain - Effective (mm/mm)

1.50

1.31

1.13

0.938

0.750

0.563

0.375

0.188

0,000

Strain-Effectuve (mmimm)

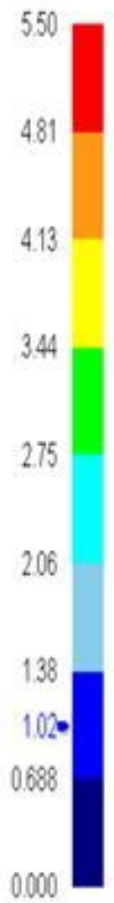

\section{Figure 2}

Varieties of extrusion forces with extrusion strokes and equivalent stresses of the AZ31 alloy during the ES process with an extrusion ratio of 12 and a preheating temperature of $370^{\circ} \mathrm{C}$, (a) upsetting, (b) sizing, (c) primary shearing, (d) secondary shearing and shaping. 


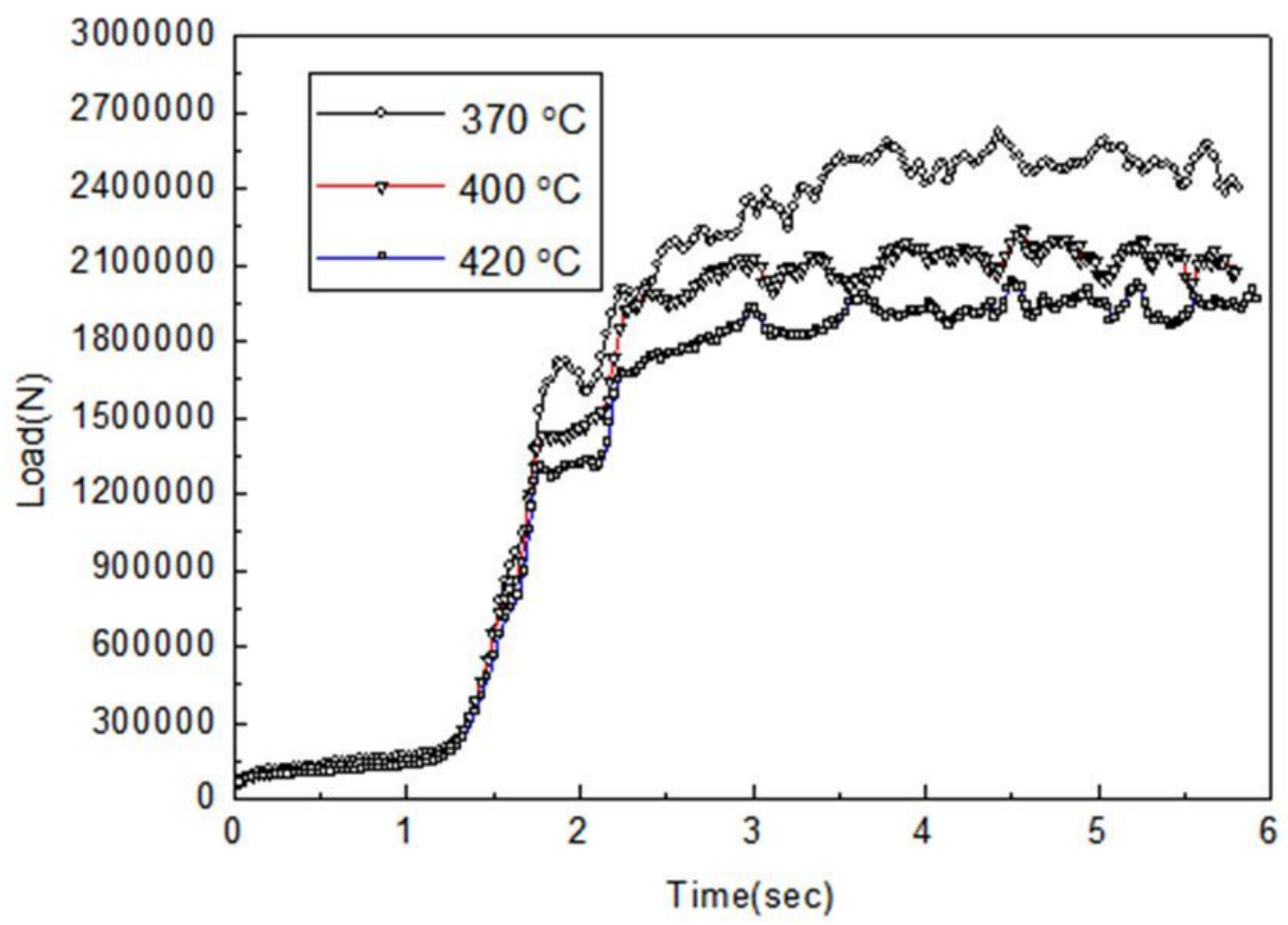

Figure 3

Extrusion forces of the ES process with different temperatures and extrusion ratios 12 


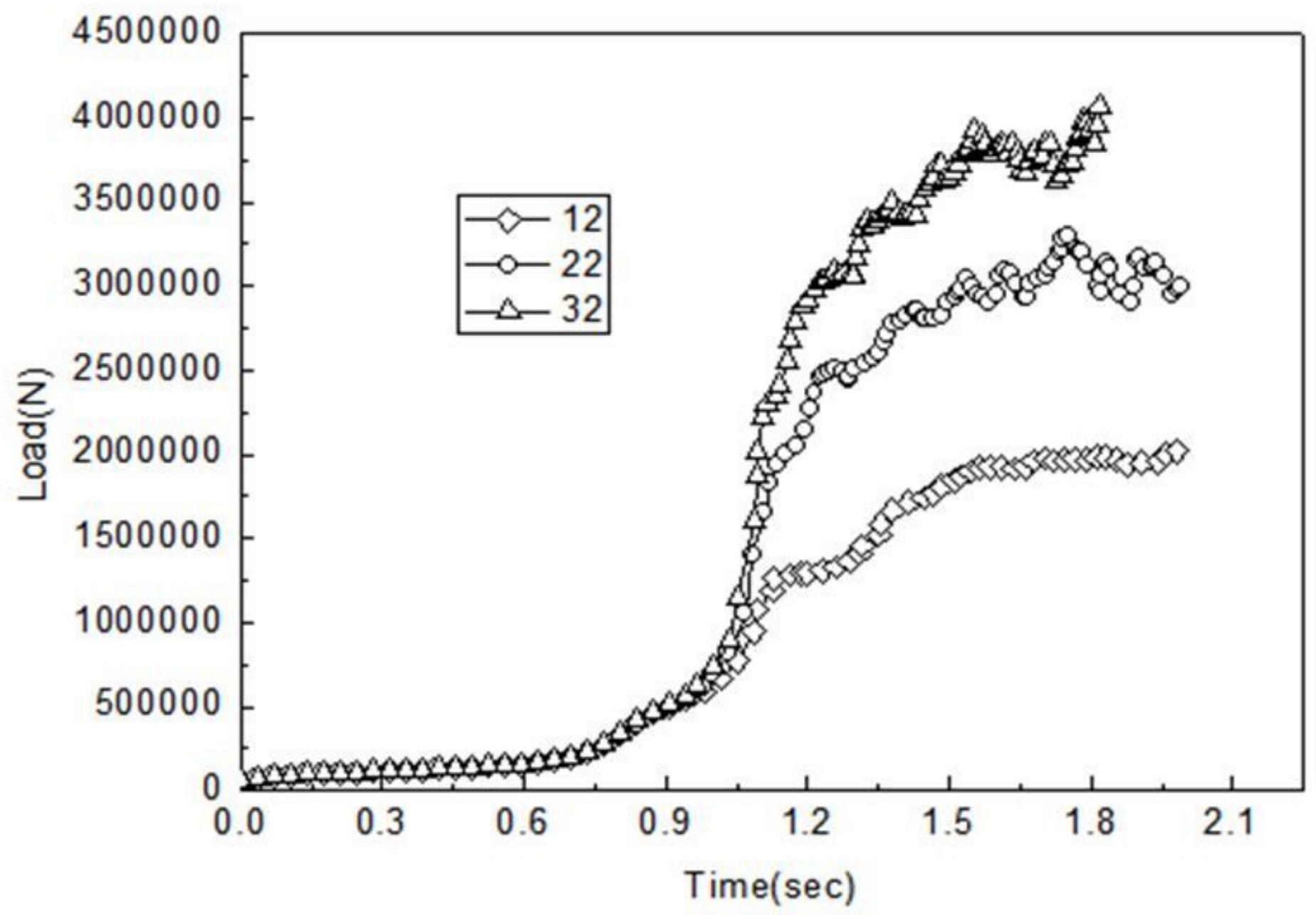

Figure 4

Extrusion forces of the ES process with different extrusion ratios 


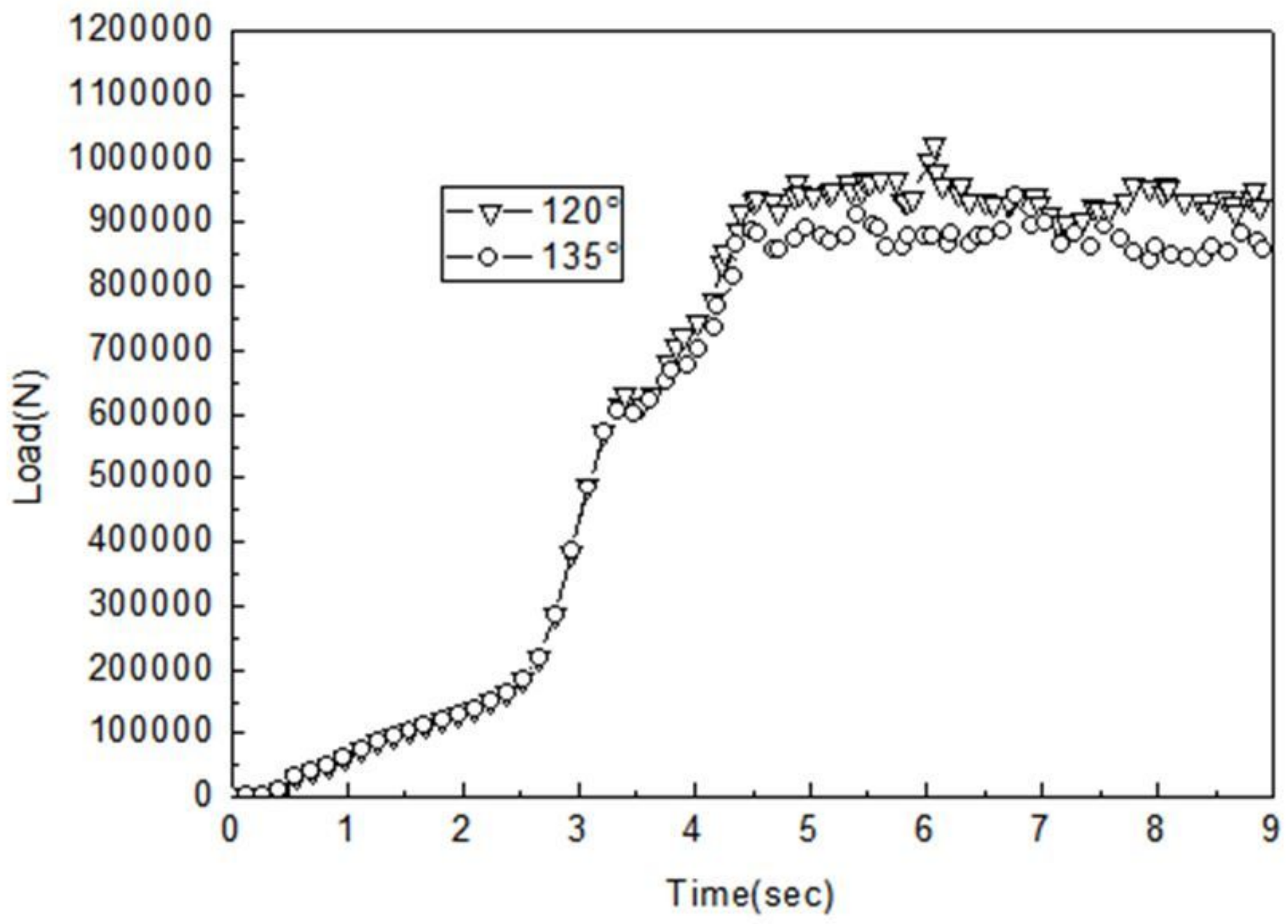

Figure 5

The changing curves of extrusion forces during the ES process with different channel angles 

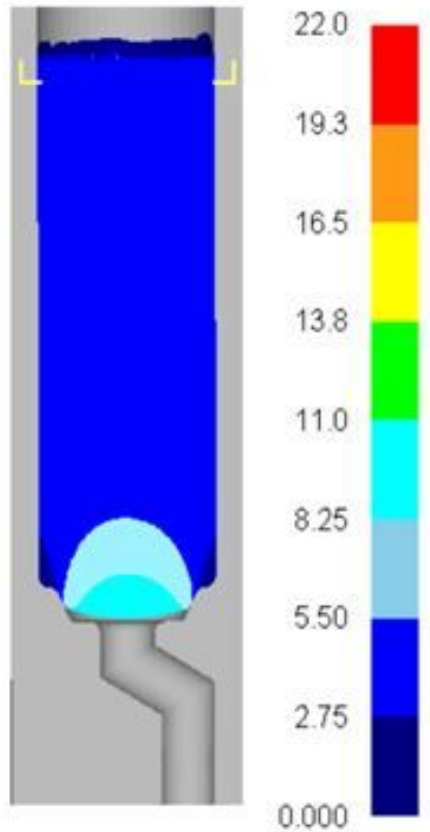

(a)

Velocity - Total vel (mm/sec)
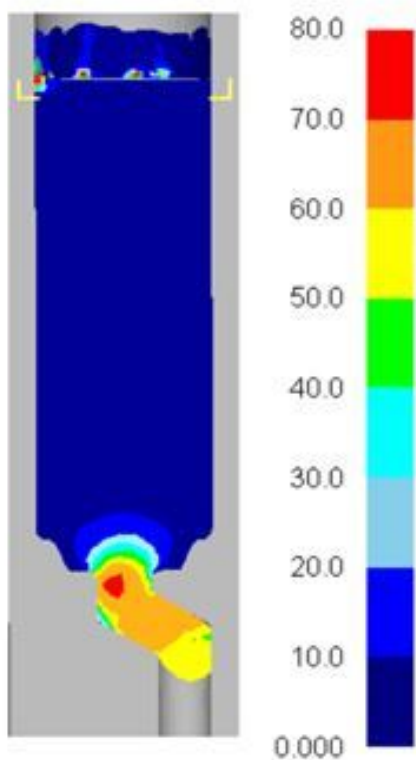

(d)

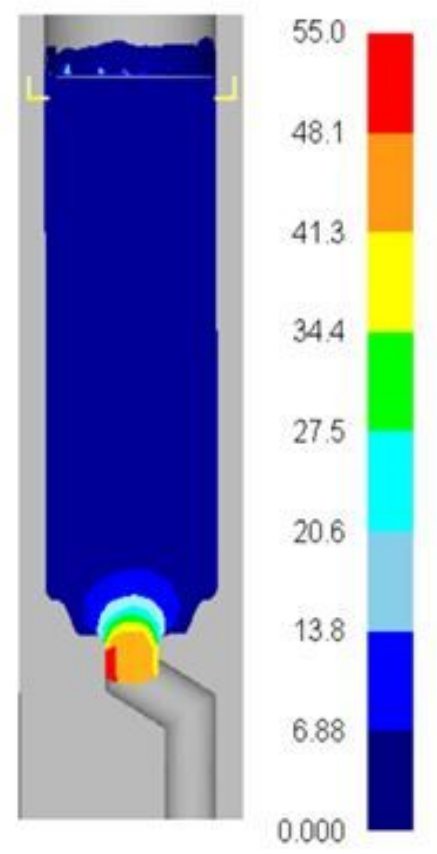

(b)

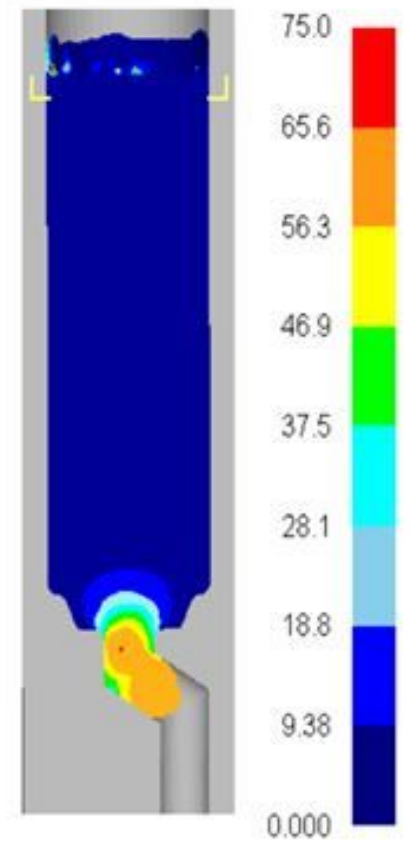

(c)

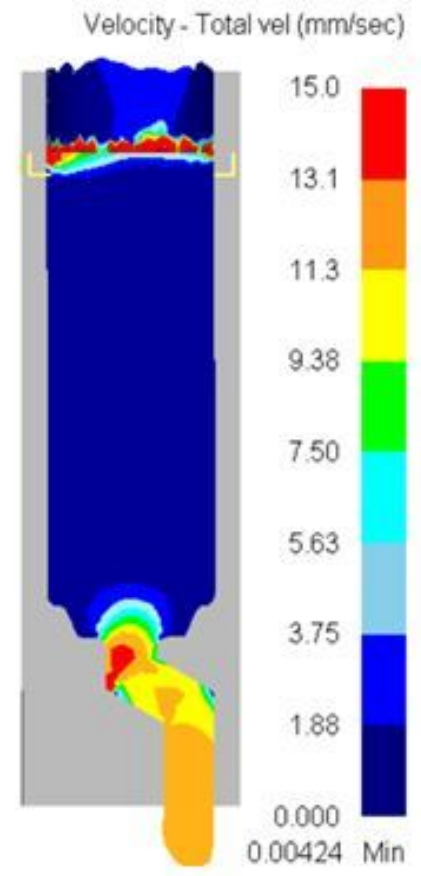

(e)

\section{Figure 6}

Distributions of metal flow velocities during different stages (a)upsetting stage, (b) ordinary direct extrusion zone, (c) primary shearing zone, (d) secondary corner region, (e)stable extrusion stage. 


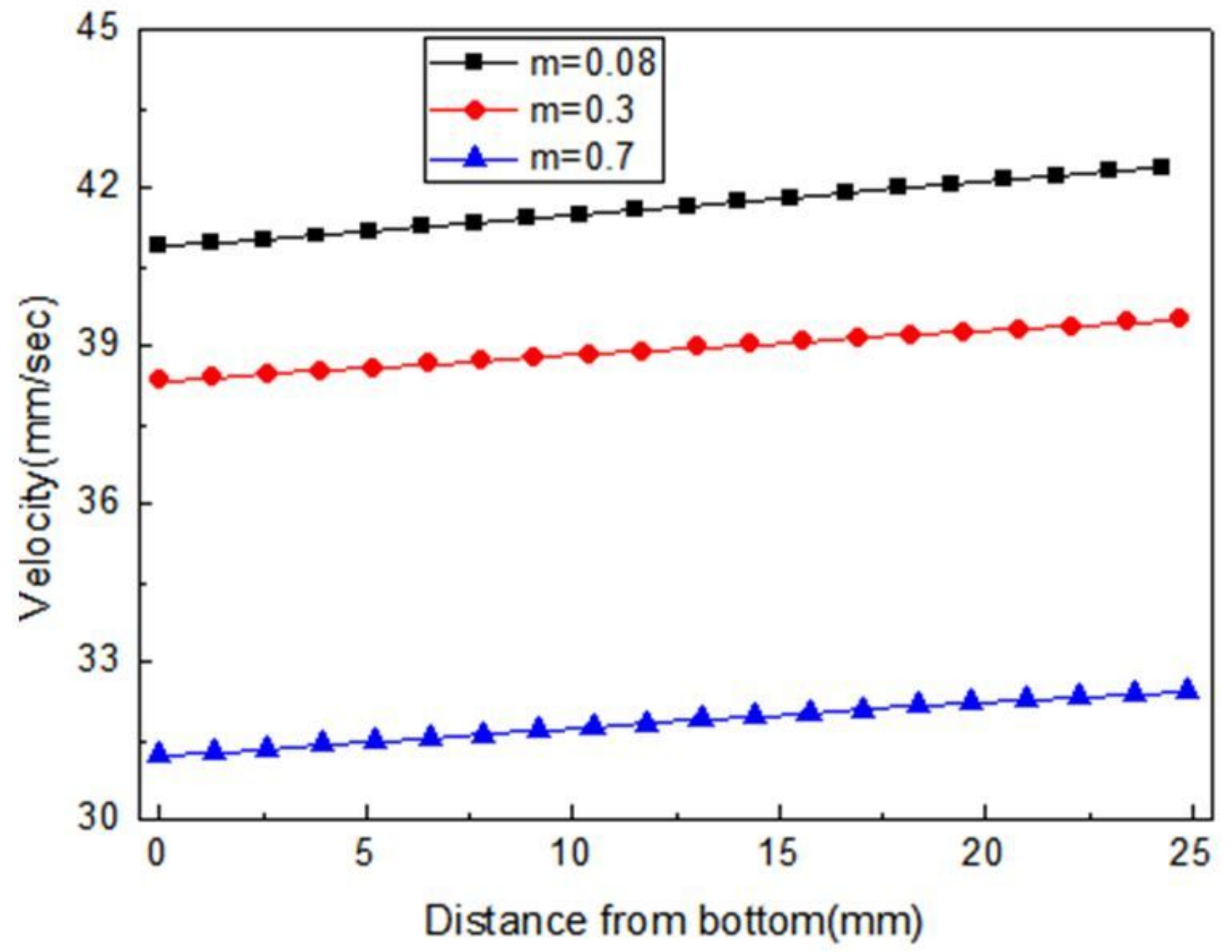

Figure 7

Effects of different friction conditions on metal flow velocities 


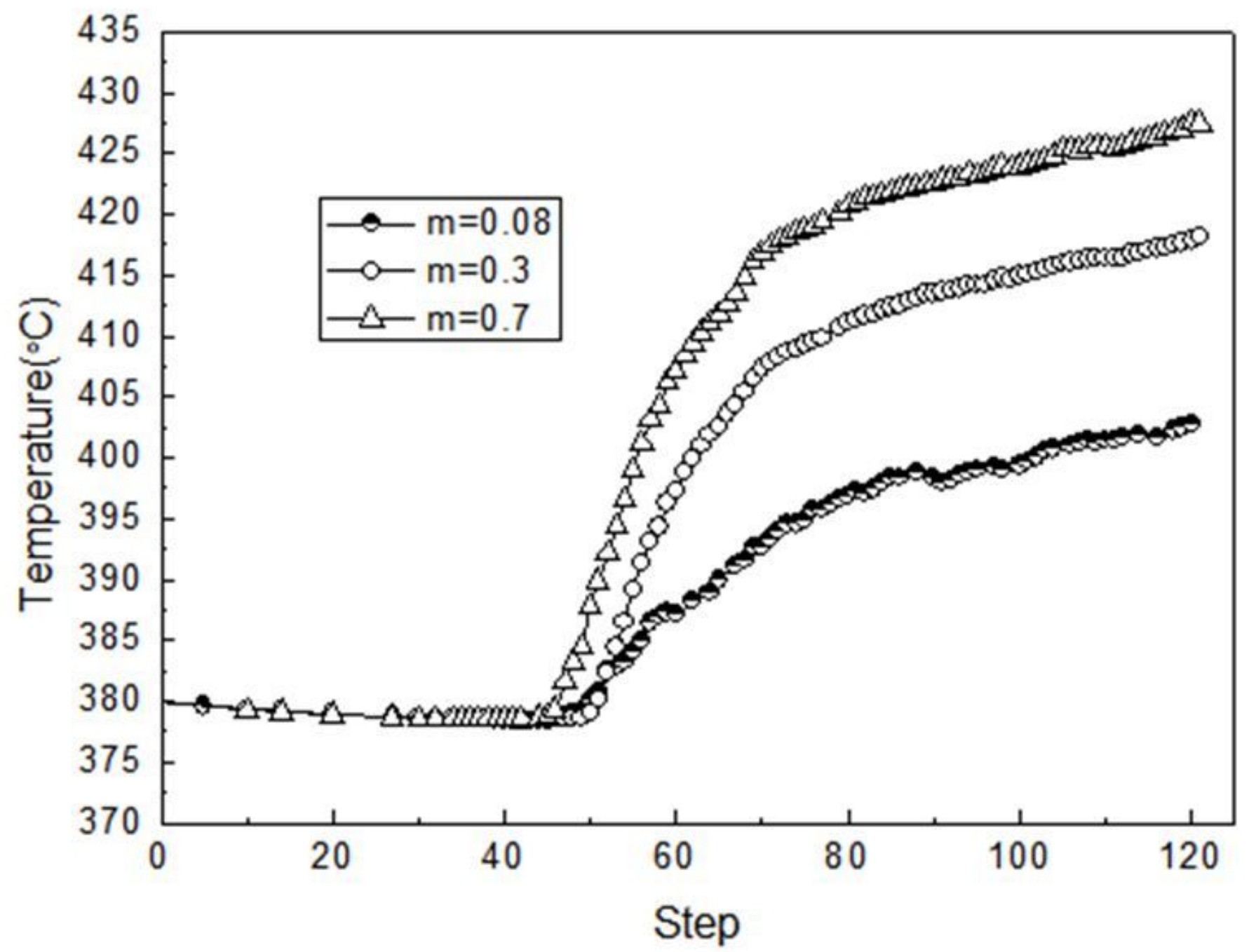

Figure 8

Temperature variations of the die with different friction conditions 


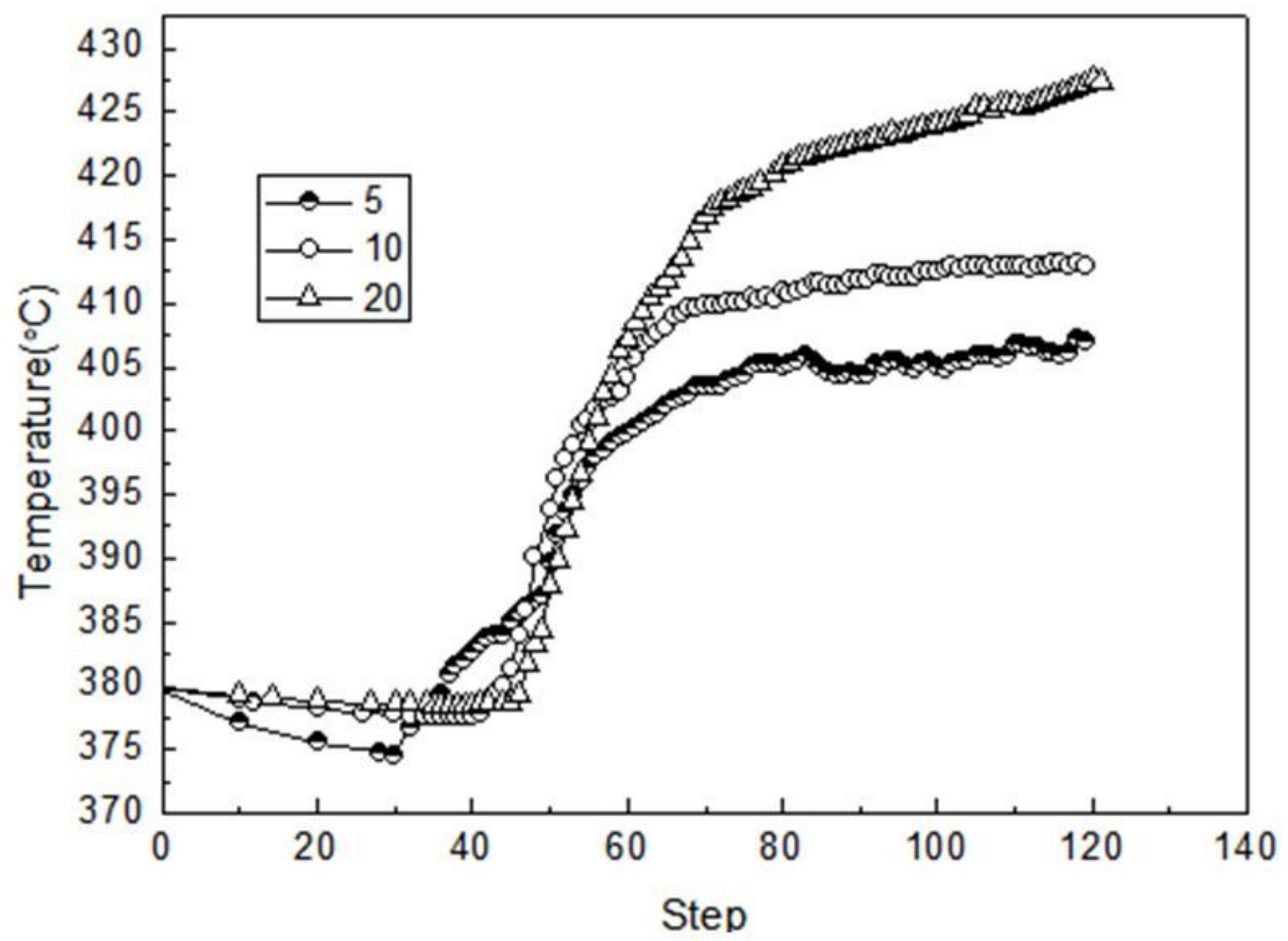

Figure 9

Temperature variations of the die with different extrusion speeds 


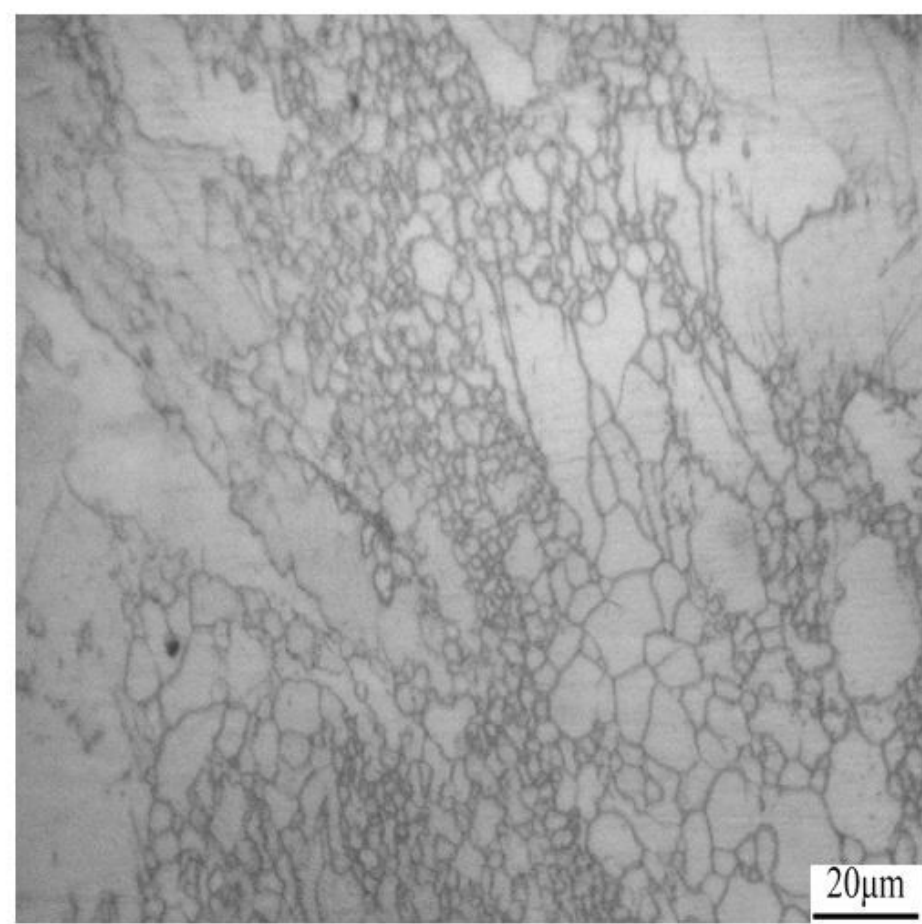

(a)

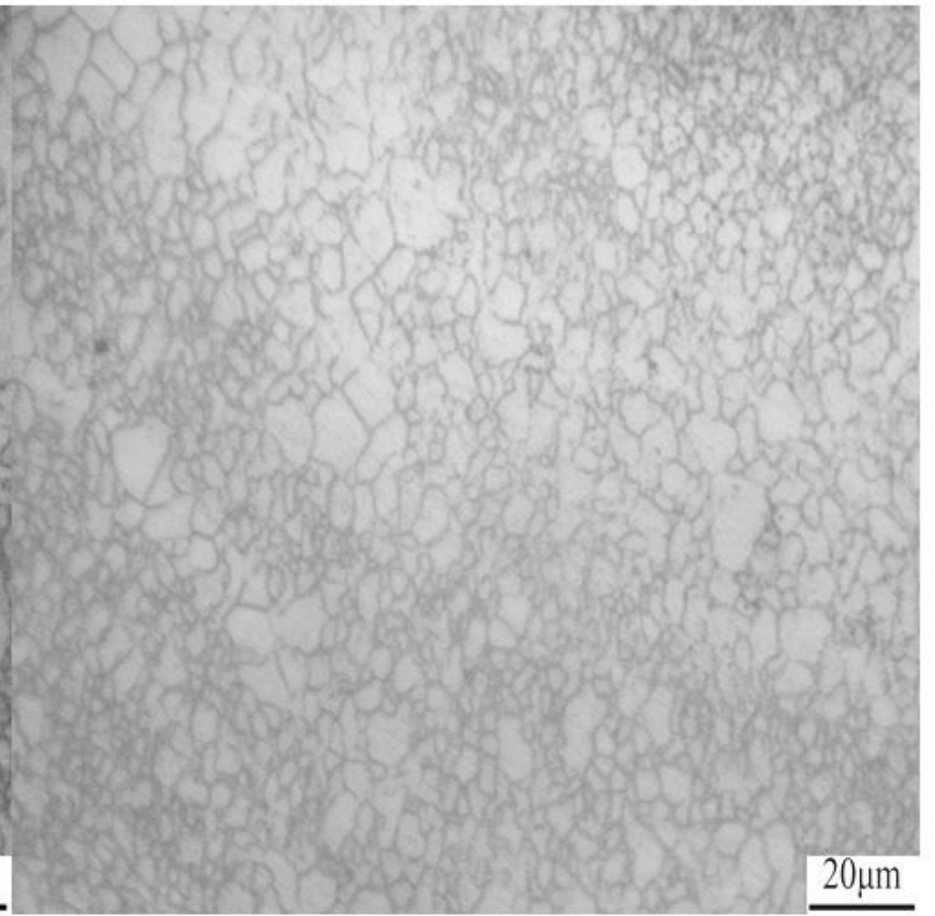

(b)

\section{Figure 10}

Microstructures of rods prepared by different processes with billets preheated at $370^{\circ} \mathrm{C}$, (a) direct extrusion and (b) ES process. 


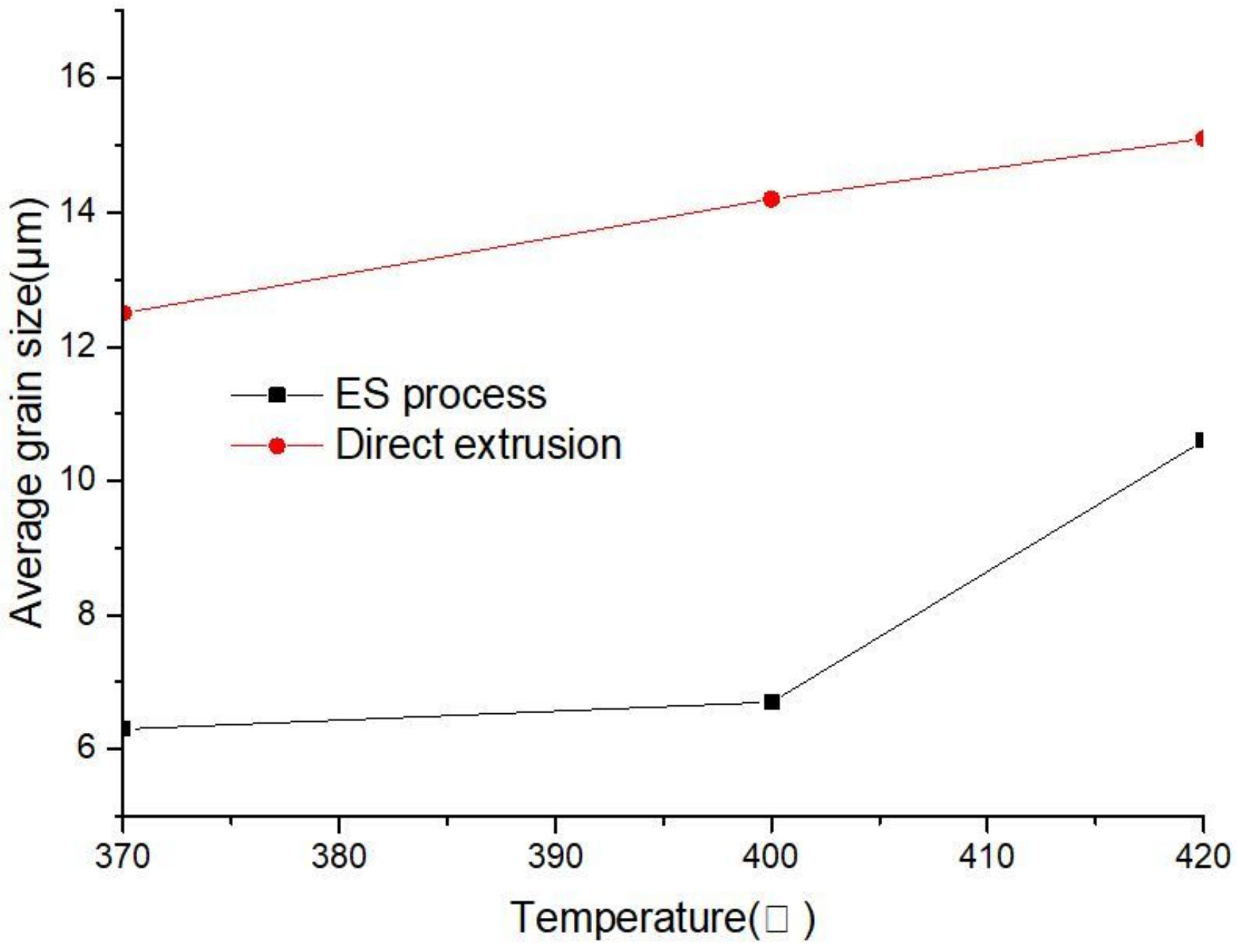

Figure 11

Average grain size of mirostructures in rods prepared by different processes with different billet preheating temperatures for direct extrusion and ES processes. 